\title{
High local unemployment and increased mortality in Danish adults; results from a prospective multilevel study
}

\author{
M Osler, U Christensen, R Lund, M Gamborg, N Godffredsen, E Prescott
}

Occup Environ Med 2003;60:el6 (http://www.occenvmed.com/cgi/content/full/60/11/el6)

See end of article for authors' affiliations

....................

Correspondence to: Professor M Osler, Department of Social Medicine, Institute of Public Health, University of Copenhagen, Blegdamsvej 3, $2200 \mathrm{~N}$, Denmark; m.osler@pubhealth.ku.dk

Accepted 13 June 2003

\begin{abstract}
Aims: To examine the relation between unemployment rates in area of residence and all-cause mortality, taking the individuals' unemployment experience and a number of social and behavioural factors into account.

Methods: Prospective cohort study with record linkage to mortality and unemployment registers. Data were pooled data from two population studies conducted in Copenhagen, Denmark. The association between unemployment at parish level and mortality was examined in Cox proportional hazard analysis. A total of 15980 men and women, aged 20-67 years and employed at 1 January 1980, were studied. All-cause mortality was followed from January 1981 to December 1998.

Results: The unemployment rate in the area of residence was associated with increased mortality (hazard ratiohighest $v$ lowest quartile 1.35:0.14-1.60) even after adjustment for individuals' unemployment experience in 1980, which was also a risk factor (hazard ratio ${ }_{\text {yes } / n o} 1.38: 1.16-1.64$ ). These estimates attenuated somewhat when other social and behavioural covariates were taken into account. The effects were similar in men and women, but the influence of individuals' unemployment experience during one and five years decreased gradually with increasing age.

Conclusion: This prospective study suggests that high local unemployment and individuals' experience of unemployment increase mortality risk, even after adjustment for other social and behavioural factors.
\end{abstract}

ndividuals' unemployment experience has been associated with a $20-30 \%$ excess in all-cause mortality in several cohort studies. ${ }^{12}$ Further, a number of ecological studies have shown that local rates of unemployment correlate positively with mortality. Local unemployment is believed to reflect the level of stress due to job insecurity, dilapidated housing, and lack of coherence, and it is used an indicator in several deprivations scores. ${ }^{3}$ However, whether living in an area with a high unemployment rate influences individuals' health independent of their own experience of unemployment is scarcely investigated. The 10 year follow up of men in the Office of Population Censuses and Survey (OPCS) showed that men seeking jobs in the region with the highest unemployment rate $(4.6 \%)$ had higher mortality than men seeking jobs in the region with the lowest unemployment rate $(3.0 \%) .{ }^{4}$ However, a Danish study based on census data from 1970-80 showed that in both men and women the relative mortality among the unemployed tended to decrease with increasing unemployment rate in 275 municipalities (range of unemployment rate $0.4-2.0 \%) .^{5}$ These two studies did not relate area unemployment to mortality risk, but a Dutch study among 8506 adults, ${ }^{6}$ has shown that subjects living in a neighbourhood with a high percentage of unemployed/disabled persons have higher mortality risk than those living in a neighbourhood with a low percentage of unemployed/disabled persons. This relation was independent of individuals' unemployment/disability status, but the ORs were not adjusted for other risk factors. Furthermore, a recent study ${ }^{7}$ has shown that individuals' unemployment experience is significantly related to perceived health. This association did not vary among contexts and contextual unemployment was not related to perceived health.

In the present study we examine the effects of the unemployment rate in the area of residence and individuals' immediate and long term experience of unemployment on later mortality in a period in the 1980s with relatively high unemployment rates. The risk estimates were adjusted for a number of social and behavioural risk factors, and we examined whether the local unemployment level modified the effect of individuals' unemployment experience on mortality.

\section{METHODS \\ Participants}

The study is based on pooled data from two prospective population studies conducted in and around Copenhagen. The Copenhagen City Heart Study ${ }^{8}$ comprises 14119 randomly selected men and women aged 20-93 years who were examined in 1976-78 and again in 1981-83, when 1560 new subjects were included. The Glostrup Population Study, ${ }^{9}$ from which one birth cohort (1936) and the MONICA surveys (born in the period 1922-62) 10 $^{10}$ were used, consisted of 8219 subjects examined first between 1976 and 1992. Thus, our study comprises 23899 adults. All examinations included a self administered questionnaire containing questions related to health and lifestyle, as well as a detailed physical examination following standardised procedures. These have been described in detail previously. ${ }^{8-10}$

Subjects were followed from 1 January 1981 until 15 December 1998 for total mortality in the National Central Person Register.

\section{Data}

The study population was linked to registers with socioeconomic information in Statistics Denmark ${ }^{11}$ using the person identification number as a key. Information on occupation and education were obtained for all study participants. Since 1980 the Register of Unemployment Statistics has gathered information on every person who is or has been member of a state recognised unemployment

Abbreviations: BMI, body mass index; HR, hazard ratio 
Main messages

- A clear positive association between local unemployment rates and all-cause mortality remains after adjustment for individuals' unemployment experience and a number of behavioural risk factors.

- The experience of unemployment increases mortality risk in men and women less than 60 years of age.

- The risk associated with individuals' unemployment status increases with the number of years unemployed and persists after excluding deaths occurring up to two years after follow up was started.

fund, and other persons who are or have been notified to a public employment office as job seekers. From this Register, which covers more than $98 \%$ of the labour force and includes all unemployment episodes for each individual, we obtained information on the experience of unemployment in 1980 and the duration of all unemployment episodes in a five year period from 1980 to 1985.

Area based information was obtained by aggregating information for 1980 for the whole population (around 1.1 million) in the study area at parish level. The 153 parishes had 250-10 500 inhabitants in the labour force in 1980. The rate of unemployment was calculated for each parish as the number of subjects who were unemployed in the year under study divided by the number of individuals in the labour force in the area.

Information on type of individual's household (recoded into two categories: single or cohabiting) and highest educational degree earned was also derived from registers in Statistics Denmark. The latter information was divided into four categories: only basic school; completed high school; short vocational educations ( $<2$ years; for example, technician, nursery teacher), and vocational educations of longer duration ( $\geqslant 2$ years; for example, schoolteacher, nurse, college and university degrees).

Standard risk factors were assessed at the baseline examination (1976-92). Body mass index (BMI) was calculated as weight $(\mathrm{kg})$ divided by squared height $(\mathrm{m})$. Study participants were categorised as non-smokers (never, ex-, or current smokers (smoking 1-14 g/day, 15-24 g/day, or $25+\mathrm{g} /$ day)). Alcohol consumption was classified in categories according to average weekly intake: $<1$ drinks, 1-6.9 drinks, 7-13.9 drinks, 14-27.9 drinks, 28-41.9 drinks, 42-69.9 drinks, >70 drinks; one drink contained 9-13 g alcohol. Physical activity in leisure time was classified into three categories: sedentary; moderate activity, $\leqslant 4$ hours per week; and moderate activity $>4$ hours per week.

\section{Statistical methods}

Cox's proportional hazards regression models were fitted to calculate the hazard ratios (approximate relative risks) of the association between unemployment and mortality with age as the underlying time scale and delayed entry (left truncation). All analyses were stratified by gender, thus assuming equal effects of coefficients for the variable of interest, but allowing baseline hazards to differ. The proportional hazards assumption was evaluated for all variables by comparing estimated log-log survivor curves over the different categories of the variables being investigated and by tests based on the generalisation of Grambsch and Therneau. ${ }^{12}$ This revealed a violation of the proportional hazard assumption with respect to individuals' unemployment (the effects of unemployment was not constant over time/age), which was then treated in models that allowed age

\section{Policy implications}

- Area unemployment rates seems to be a marker for areas that need special attention.

- It is important to improve the individual's chances for re-employment and to develop the labour market in the relatively deprived communities.

to interact with unemployment. Because the number of participants in each area varied and those belonging to the same area are more likely to be alike, data were analysed using a robust estimator of variance. ${ }^{13}$ Statistical interaction between area and individuals' unemployment was performed using the likelihood ratio test. Statistical analyses were performed using STATA for Unix version 7.

\section{RESULTS}

We excluded subjects $(\mathrm{n}=9605)$ who were more than 67 years of age or who were not in the labour force 1 January 1980. In the analysis of the potential effects of number of years of unemployment over a five year period, an additional 2018 subjects who reached the age of 67 years before 1 January 1986 were excluded. Among the remaining 15980 participants, 2861 died during follow up. Of the 11770 men and women left for the analysis of cumulative effects, 1318 had died at follow up.

The local unemployment rate was 9.7\% (range 3.5-24.9\%). Fifteen per cent of men and women had experienced some unemployment in 1980, and $26 \%$ had been unemployed between 1980 and 1986. All the other covariates were associated with both area and individual unemployment (table 1). Thus, study participants living in high unemployment areas were more often smokers, sedentary during leisure, had a high alcohol consumption, and a BMI $>30 \mathrm{~kg} / \mathrm{m}^{2}$ compared to those who lived in areas with low rates of unemployment. They were also more often living single and less educated. A similar pattern of associations was found between covariates and individuals' unemployment experience.

Local unemployment and individuals' experience of unemployment in 1980 were both positively associated with mortality (table 2 ). The relation between local unemployment and mortality was unaffected by the inclusion of individuals' unemployment in the model, while the estimates for both variables attenuated when other social and behavioural covariates were entered. The effect of individuals' unemployment on mortality did not vary in relation to rates of unemployment in the area of residence (no significant interaction), but it was modified by age. The effect gradually decreased with increasing age, and was highest in the youngest age group $\mathrm{HR}_{\text {age }}$ 19-30 1.94:1.06-3.53 and lowest in the oldest age group HR age 60-67 0.96:0.77-1.19. Long term unemployment measured as the number of years individuals had been unemployed between 1980 and 1986 was related to mortality in a dose dependent manner in men and women less than 60 years of age (fig 1). Visual evaluation of mortality rates in categories of unemployment in the different age groups did not indicate any additive modifications of effects. We also carried out analyses that omitted events in the first two years of follow up (not shown). This procedure did not significantly change the reported associations.

\section{DISCUSSION}

In this prospective study of almost 15000 adults from a metropolitan area with high rates of unemployment we found that local unemployment rates and individuals' 
Table 1 The distribution of covariates' relation to local unemploments rates and individuals' unemployment experience in 1980 in men and women in employment on 1 January 1980

\begin{tabular}{|c|c|c|c|c|}
\hline & \multicolumn{2}{|c|}{ Local unemployment } & \multicolumn{2}{|c|}{ Individuals' unemployment experience } \\
\hline & $\begin{array}{l}\text { Lowest } \\
\text { unemployment } \\
\text { quartile } \\
r=3.5-6.6 \%\end{array}$ & $\begin{array}{l}\text { Highest } \\
\text { unemployment } \\
\text { quartile } \\
r=12.0-24.9 \%\end{array}$ & No unemployment & $\begin{array}{l}\text { Some (1 day- } \\
12 \text { months) } \\
\text { unemployement in } \\
1980\end{array}$ \\
\hline Number of participants & 2013 & 3274 & 13323 & 2397 \\
\hline$\%$ smokers & 53.0 & 67.1 & 60.0 & 67.4 \\
\hline $\begin{array}{l}\% \text { drinking }>28 \text { drinks } \\
\text { per week }\end{array}$ & 6.3 & 11.7 & 8.0 & 17.3 \\
\hline$\%$ sedentary leisure & 23.0 & 24.4 & 20.9 & 25.6 \\
\hline$\%$ with $\mathrm{BMI}>30 \mathrm{~kg} / \mathrm{m}^{2}$ & 8.6 & 11.2 & 9.5 & 12.0 \\
\hline$\%$ living single & 18.4 & 34.5 & 28.3 & 37.5 \\
\hline $\begin{array}{l}\% \text { with basic educational } \\
\text { degree }\end{array}$ & 31.6 & 51.4 & 40.1 & 51.1 \\
\hline
\end{tabular}

unemployment experience were both associated with increased all-cause mortality after adjustment for a number of social and behavioural factors. The relation between unemployment and mortality at the individual level is well established, ${ }^{12-5}$ and our risk estimates were consistent with previous studies. The present study also showed that the effect increased with the number of years unemployed in both men and women. The mechanisms by which unemployment can affect health involve material circumstances (financial strain), psychosocial factors, and selection. The reduction in income that accompanies job loss is typically large enough to require substantial financial adjustments by those involved. This seems to lead to both material deprivation and psychological distress. Occupation is considered one of the core social roles with profound impact on the individuals' sense of self-esteem and integration. ${ }^{14}$ It has been suggested that the role of work and losing a job is less important for women than for men. ${ }^{15}$ The present and a recent Swedish study ${ }^{16}$ do not support this hypothesis, since the increased mortality after unemployment was evident among women in both studies. Similar to the results from previous census based studies in Denmark $^{17}$ and other countries, ${ }^{1}$ the effect of unemployment on mortality decreased with increasing age. This might reflect that the

Table 2 Hazard rate ratios $(95 \% \mathrm{Cl})$ of all-cause mortality in employed men and women aged 20-93 years by unemployment experience

\begin{tabular}{|c|c|c|c|}
\hline & Unadjusted & $\begin{array}{l}\text { Adjusted for } \\
\text { individual level }\end{array}$ & $\begin{array}{l}\text { Other individual variables* } \\
\text { in model }\end{array}$ \\
\hline & \multicolumn{3}{|l|}{15980 subjects (2861 deaths) } \\
\hline \\
\hline & \multicolumn{3}{|c|}{ Unemployment rate } \\
\hline 1 st quartile (3.5-6.6\%) & 1 & 1 & 1 \\
\hline 2nd quartile (6.6-8.8\%) & 1.14 (0.97 to 1.35 ) & 1.14 (0.97 to 1.35$)$ & 1.11 (0.93 to 1.32$)$ \\
\hline 3rd quartile (8.8-12.0\%) & $1.22(1.02$ to 1.49$)$ & 1.21 (1.01 to 1.44$)$ & $1.12(0.92$ to 1.36$)$ \\
\hline 4th quartile (12.0-24.9\%) & 1.38 (1.16 to 1.63 ) & $1.35(1.14$ to 1.60$)$ & $1.16(0.97$ to 1.37$)$ \\
\hline & $p<0.001$ & $p<0.001$ & $p=0.082$ \\
\hline \multirow{2}{*}{\multicolumn{4}{|c|}{$\begin{array}{l}\text { Individual level } \\
\text { Unemployed in } 1980\end{array}$}} \\
\hline & & & \\
\hline \multicolumn{4}{|l|}{ No $(85 \%)$} \\
\hline \multirow[t]{2}{*}{ Yes $(15 \%)$} & 1.35 (1.23 to 1.49 ) & 1.34 (1.21 to 1.47$)$ & 1.24 (1.11 to 1.37$)$ \\
\hline & \multicolumn{3}{|l|}{11770 subjects (1318 deaths) } \\
\hline \multirow{2}{*}{\multicolumn{4}{|c|}{$\begin{array}{l}\text { Area level } \\
\text { Unemployment rate }\end{array}$}} \\
\hline & & & \\
\hline 1 st quartile $(3.5-6.6 \%)$ & 1 & 1 & 1 \\
\hline 2nd quartile (6.6-8.8\%) & 1.23 (1.04 to 1.45 ) & 1.21 (1.03 to 1.43$)$ & $1.14(0.76$ to 1.39$)$ \\
\hline 3rd quartile (8.8-12.0\%) & 1.29 (1.06 to 1.58$)$ & $1.27(1.04$ to 1.55$)$ & 1.25 (1.02 to 1.54$)$ \\
\hline \multirow{2}{*}{ 4th quartile (12.0-24.9\%) } & $1.43(1.20$ to 1.71$)$ & 1.38 (1.16 to 1.64$)$ & 1.23 (1.03 to 1.46$)$ \\
\hline & $p<0.001$ & $p<0.001$ & $p=0.033$ \\
\hline \multirow{3}{*}{\multicolumn{4}{|c|}{$\begin{array}{l}\text { Individual level } \\
\text { Number of years unemployed } \\
1980-85\end{array}$}} \\
\hline & & & \\
\hline & & & \\
\hline No $(73.3 \%)$ & 1 & 1 & 1 \\
\hline$<1$ y $(15.6 \%)$ & 0.99 (0.84 to 1.17 ) & $0.98(0.83$ to 1.16$)$ & $0.91(0.76$ to 1.09$)$ \\
\hline $1-2$ y $(5.3 \%)$ & $1.40(1.12$ to 1.75$)$ & 1.38 (1.10 to 1.73 ) & $1.16(0.92$ to 1.47$)$ \\
\hline \multirow[t]{2}{*}{$2-6$ y $(5.9 \%)$} & $1.74(1.47$ to 2.06$)$ & 1.70 (1.43 to 2.02 ) & $1.45(1.21$ to 1.74$)$ \\
\hline & $\mathrm{p}<0.001$ & $p<0.001$ & $p<0.001$ \\
\hline $\begin{array}{l}\text { Results from Cox's proportion } \\
\text { p values: test for linear trend. } \\
\text { *Adjusted for factors in table } \\
\text { four categories), daily alcohol } \\
\text { four categories). }\end{array}$ & $\begin{array}{l}\text { nal hazard models stratified by s } \\
\text { and smoking status (in five cate }\end{array}$ & sex and with age as u & $\begin{array}{l}\text { underlying time scale. } \\
\text { ity (sedentary, active), BMI (in } \\
\text { categories), and education (in }\end{array}$ \\
\hline
\end{tabular}




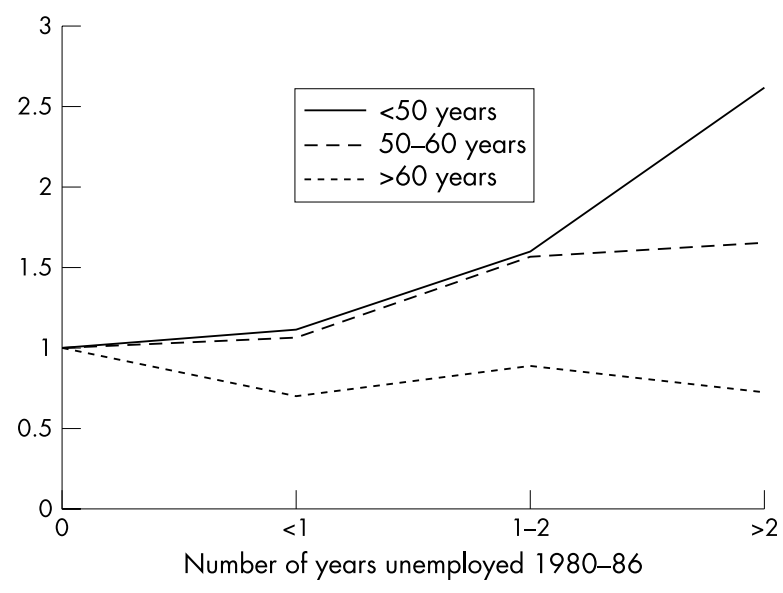

Figure 1 Hazard rate ratios of all-cause mortality in relation to number of years of unemployment and age.

economic and psychosocial consequences of unemployment are less stigmatising for older people than for those in young and middle age. We found no evidence of health selection, since the association was stronger in the youngest age groups and persisted after inserting a "time window" before analysis by excluding deaths appearing up to two years after follow up was started. Further, the gradual increase in unemployment in Denmark during the 1970s might already have excluded the unhealthy subjects from the labour force.

Few previous studies have explicitly examined the effect of the local unemployment rates on individuals' health, and the results have been conflicting. This might be due to the fact that studies had differed with regard to design, outcome, context level, and measure of unemployment. Some studies have addressed how the job market influences the health effects of individual unemployment. One study has suggested that the effects of individual unemployment on health are stronger in low unemployment areas, ${ }^{5}$ another has shown the opposite effect, ${ }^{4}$ while others, ${ }^{6}$ as with the present study, found no such interaction. A recent Finnish study found that the association between unemployment and mortality weakened as the general unemployment rate increased from less than $5 \%$ in early 1990 to around $20 \%$ in late $1992 .{ }^{18}$ The rates of unemployment were high in the present study compared to those reported elsewhere, ${ }^{45}$ and we cannot exclude that a modification of the health effects of individual unemployment could be present at a lower general level of unemployment. We are only aware of one study which has reported that unemployment in local area of residence influences individuals' mortality besides effects from individual unemployment experience. ${ }^{6}$ The present study supports this finding, and further adds that the relation persists after controlling for social and behavioural factors which might be considered as confounders. One explanation for the presumed contextual effects of unemployment opportunity is that there may be "area" effects due to factors related to unemployment rates. Areas with high rates of unemployment are more likely to be characterised by general poverty, poor housing conditions, and higher incidence of other life events. In the present study additional analyses, not presented, suggested that area based unemployment was correlated with other aspects of the area, such as educational level and mean income. However, the effect on individual health persisted when other contextual factors were controlled for. This suggests that high unemployment areas need special social and health political attention. Alternative explanations could be linked to the concept of social capital. According to this theory, area based income inequality, which might also include high rates of unemployment, leads to disinvestment in human infrastructure and social capital, which is associated with increased mortality. ${ }^{19}$ However, parishes in Copenhagen might not differ substantially with regard to this aspect, since the overall social policy in Copenhagen includes equal access to most public services. At a macro level, there was a worsening of the economy in 1979 with a rise in the unemployment rate. In 1982 a liberal government replaced the social democratic one, and even though this change of government did not bring any marked change in the overall welfare policies in the country, reductions of the unemployment benefits were implemented. From 1982 to 1987 the purchasing power of the unemployment benefit fell by $17 \%$, and the waiting period for obtaining the right to unemployment benefit was lengthened. These reductions hit the youngest part of the labour force the most. Thus, to understand the effects of unemployment in this study it seems relevant to include the specific historical context as well; a limitation of our study was that the unemployment status of the individual and area was documented over a short period of time only. On the other hand, our study was based on register data, which might limit misclassification due to reporting errors.

In conclusion, data from this prospective study suggest that unemployment at both the contextual and individual level are associated with increased mortality after adjustment for other social and behavioural covariates. It seems to be important not only to improve the individual's chances for reemployment, but also to develop the labour market in the relatively deprived communities.

\section{ACKNOWLEDGEMENTS}

Contributors: Merete Osler had the original idea for the present study and wrote the paper. Merete Osler and Eva Prescott established the linkage of the data set to Statistics Denmark. Michael Gamborg was responsible for the data analyses. Eva Prescott, Ulla Christensen, Rikke Lund, and Nina Godtfredsen commented on the earlier drafts and helped interpret the findings. Merete Osler is guarantor.

\section{Authors' affiliations}

M Osler, U Christensen, R Lund, Department of Social Medicine, Institute of Public Health, University of Copenhagen, Blegdamsvej 3, 2200 N, Denmark

M Gamborg, N Godffredsen, E Prescott, The Copenhagen Centre of Prospective Population Studies, Danish Epidemiology Science Centre at the Institute of Preventive Medicine, HS: Copenhagen University Hospital, 1399 Copenhagen, Denmark

Funding: Danish Heart Association and Danish Health Research Council

\section{REFERENCES}

1 Kasl S, Jones BA. The impact of job loss and retirement on health. In: Berkmann L, Kawachi I, eds. Social epidemiology. London: Oxford University Press, 2000.

2 Wilson SH, Walk GM. Unemployment and health: a review. Public Health 1993; 107:153-62.

3 Jolley DJ, Jarmann B, Elliott P. Socioeconomic confounding. In: Elliott P, Cuzick J, English D, eds. Geographical and environmental epidemiology. Methods for small-area studies. Oxford University Press, 1992.

4 Moser KA, Fox AJ, Jones DR, et al. Unemployment and mortality: further evidence from the OPCS Longitudinal study. Lancet 1986;1:365-7.

5 Iversen L, Andersen O, Andersen PK, et al. Unemployment and mortality in Denmark, 1970-80. BMJ 1987:295:879-84.

6 Bosma H, van de Mheen D, Borsboom GJJM, et al. Neighborhood socioeconomic status and all-cause mortality. Am J Epidemiol $2001 ; 153: 363-71$.

7 Béland F, Birch S, Stoddart G. Unemployment and health: contextual-level influences on the production of health in populations. Soc Sci Med 2002;55:2033-52.

8 Appleyard M, Hansen AT, Schnohr P, et al. The Copenhagen City heart Study. A book of tables with data from the first examination (1976-78) and 5-year follow-up (1981-83). Scand J Soc Med 1989;170:1-160.

9 Hagerup L, Schroll M, Hollnagel H, et al. The Glostrup Population Study. Collection of Epidemiological Tables. Reference values for use in cardiovascular population studies. Scand J Soc Med 1981;(suppl 20):5-112. 
10 Gerdes LU, Brønnum-Hansen $\mathrm{H}$, Madsen $\mathrm{M}$, et al Trends in selected biological risk factors for cardiovascular disease in the Danish MONICA-population 1982-1992. J Clin Epidemiol 2001;53:548-55.

11 Statistics on Persons in Denmark. A register-based statistical system. Luxembourg: Eurostat, 1995.

12 Grambsch PM, Therneau TM. Proportional hazard tests and diagnostics based on weighted residuals. Biometrika 1994;81:515-26.

13 Rogers WH. Regression standard errors in clustered samples. Stata Technical Bulletin 1993; 13:19-23.

14 Siegrist J. Place, social exchange and health: proposed sociological framework. Soc Sci Med 2000;51:1283-93.
15 Stephanson CG. Long-term unemployment and mortality in Sweden, 1980-6. Soc Sci Med 1991;32:419-23.

16 Nylen L, Voss M, Floderus B. Mortality among women and men relative to unemployment, part time work, overtime work, and extra work: a study based on data from the Swedish twin study. Occup Environ Med 2001 58:52-7.

17 Ingerslev O, Madsen M, Andersen O. Social differences in mortality in Denmark. Danish Ministry of Health, 1994.

18 Martikainen PT, Valkonen T. Excess mortality of unemployed men and women during a period of rapid increasing unemployment. Lancet 1996;348:909-12.

19 Kawachi I, Berkmann LF. Social cohesion, social capital, and health. In: Berkmann LF, Kawachi I, eds. Social epidemiology. Oxford University Press, 2000. 